\title{
Who can do without patients?
}

\author{
Olle ten Cate $\cdot$ Max Peters
}

Published online: 31 March 2015

(C) The Author(s) 2015. This article is published with open access at Springerlink.com

We appreciate Cantillon and Dornan's comment [1] on our observation [2] that in the medical education literature and textbooks bedside teaching is gradually disappearing. The authors make the case that beds are less functional in medical education and that teaching is not the most appropriate word for the role of clinical educators, and therefore our concern may be less alarming.

Linguistically, this may be true, but the interpretation of our message is narrower and more literal than it was meant. The deeper point of our regret is that the patient seems to become less central in workplace education. The loss of instructional texts about how to role model in the presence of patients in the sense of bedside teaching may be illustrative of the decreased educational time spent at the side of the patient in general, including in ambulatory care. Doctors and medical trainees now spend less and less time with patients [3] than in the past. A recent study found that interns spend $12 \%$ on average in direct patient care and $40 \%$ behind a computer screen. The reasons for this lie in restricted working hours, restricted time for patients in hospital settings, short rotations and an increased volume of patient data to be handled. It may to some extent be true that patients are less in bed, but predominantly students do not see them in bed. In addition, students and residents are hardly observed when working with patients and hardly observe clinicians doing this $[4,5]$.

Why is that not good? A lack of patient-related education is detrimental for the development of clinical thinking

O. ten Cate $(\bowtie) \cdot$ M. Peters

Center for Research and Development of Education, University Medical Center Utrecht,

PO Box 85500, 3508 GA Utrecht, The Netherlands

e-mail: t.j.tencate@umcutrecht.nl and reasoning skills, and for professional identity formation and professional behaviour. Clinical diagnostic decisionmaking is primarily based on pattern recognition [6], which requires extensive experience with patients. The more the better. Many valid illness scripts in the long-term memory of clinicians are needed to adequately recognize patterns or stimulate analytic reasoning. It has long been recognized that an adequate history is associated with better diagnosis and management than tests [7]. In education, seeing patients is one, but an experienced educator and role model is needed to help turn this seeing into deliberate practice [8]. Longitudinal clerkships may restore continuity in both patient care and clinical teaching [9] if we may use this word teaching to signify the variety of activities of committed clinician educators, including role modelling, coaching, stimulating reflection and allocating learning opportunities to match the student's developmental level [10].

Elder et al. recently mapped a road back to the bedside [11], or should we say, back to having clinical teachers, learners and patients together discuss medicine?

Conflicts of interest notification No conflicts of interest.

Open Access This article is distributed under the terms of the Creative Commons Attribution License which permits any use, distribution, and reproduction in any medium, provided the original author(s) and the source are credited.

\section{References}

1. Cantillon P, Dornan T. Who needs beds? Perspect Med Educ. 2014;3(5):399-400.

2. Peters M, Ten Cate O. Bedside teaching in medical education: a literature review. Perspect Med Educ. 2014;3:76-88. 
3. O’Leary KJ, Liebovitz DM, Baker DW. How hospitalists spend their time: insights on efficiency and safety. J Hosp Med. 2006;1(2):88-93.

4. Fromme HB, Karani R, Downing SM. Direct observation in medical education: a review of the literature and evidence for validity. Mt Sinai J Med. 2009;76:365-71.

5. Howley LD, Wilson WG. Direct observation of students during clerkship rotations: a multiyear descriptive study. Acad Med. 2004;79(3):276-80.

6. Croskerry P. A universal model of diagnostic reasoning. Acad Med. 2009;84(8):1022-8.

7. Sandler G. The importance of the history in the medical clinic and the cost of unnecessary tests. Am Heart J. 1980;100(6):928-31.

8. Kassirer JP. Teaching clinical reasoning: case-based and coached. Acad Med. 2010;85(7):1118-24.

9. Irby DM. Educational continuity in clinical clerkships. N Engl J Med. 2007;356(8):856-7.
10. Chen HC, Sheu L, O'Sullivan P, ten Cate O, Teherani A. Legitimate workplace roles and activities for early learners. Med Educ. 2014;48(2):136-45.

11. Elder A, Chi J, Ozdalga E, Kugler J, Verghese A. The road back to the bedside. J Am Med Assoc. 2013;310(8):799-800.

Olle ten Cate, is professor of Medical Education and Director of the Center for Research and Development of Education at University Medical Center Utrecht.

Max Peters, is a doctoral candidate at the Department of Radiotherapy at University Medical Center Utrecht 